Sharif University of Technology
Scientia Iranica
SCIENTIA
I RAN I CA
http://scientiairanica.sharif.edu

\title{
Investigation into stiffness degradation progress in glass/vinylester laminated beams under large deformations
}

\author{
A.R. Nazari ${ }^{a}$, M.Z. Kabir ${ }^{a, *}$, and H. Hosseini-Toudeshky ${ }^{b}$ \\ a. Department of Civil and Environmental Engineering, Amirkabir University of Technology, Tehran, Iran. \\ b. Department of Aerospace Engineering, Amirkabir University of Technology, Tehran, Iran.
}

Received 5 October 2015; received in revised form 2 November 2016; accepted 6 March 2017

\section{KEYWORDS}

Flexural strength;

GFRP laminate;

Progressive failure;

Hashin criteria;

Large deformations.

\begin{abstract}
There are many reports indicating that the maximum measured stress in the composite laminated beams under flexural loading is different from that under tensile loading. The current study compares the results of Hashin failure criteria in the form of stress and strain components for the prediction of failure strength in GFRP laminated beams. In the experimental program, the composite laminates were tested under tensile and three-Point-Bending (3PB) loads. Then, we tried to predict the flexural failure in laminates based on the measured ultimate stresses and strains in the tensile tests. The strain-based failure criteria employed in the FE models could achieve more admissible predictions of maximum load carrying capacity in the laminates than the stress-based criteria. Progressive failure analyses showed that due to higher elastic modulus of laminates under bending load, the maximum experienced stress under bending load became larger.

(C) 2018 Sharif University of Technology. All rights reserved.
\end{abstract}

\section{Introduction}

Increasing application of fibre reinforced polymers in various industries has prompted many researchers to develop appropriate theories for investigation into the failure criteria and estimation of the service life of composite structures in the last decades. Numerous researchers have tried to predict several modes of failure in the composite laminates by analytical and empirical formulae [1]. The dual-phase nature of these materials sometimes leads to different behaviors observed under various loading conditions. There are many reports that denote considerable differences between the mechanical properties of composite laminates under

\footnotetext{
*. Corresponding author. Tel.: +982164543016;

Fax: +98 2166959020

E-mail address: mzkabir@aut.ac.ir (M.Z. Kabir)
}

bending and tensile loads. These differences are concerned when composite laminates are subjected to outof-plane loads [2]. For example, the ultimate flexural strength has sometimes been measured larger than the tensile strength. Bullock [3] reported the ratio of the strength measured under three-Point-Bending (3PB) to the strength measured in tensile tests to be 1.35 and 1.49 for two types of graphite-epoxy composites. Whitney and Knight [4] measured this ratio as 1.33 for graphite-epoxy laminates. Weibull theory [3] predicts higher strength in bending than in tension loading by assuming that the strength is controlled by the critical defects which are statistically distributed in the material. Since under bending test, a smaller volume of the material is subjected to the maximum stress, usually, higher flexural strength is measured for the composite laminates. Cattell and Kibble [5] tested 3PB beams with span to depth ratio $(L / D)$ equal to 20 and measured the ratio of flexural to tensile strength equal to 1.4. Then, they tried to predict this ratio by Weibull 
theory. The results of this theory are mostly dependent on the assumed flaw distribution in the material, which is introduced by Weibull modulus. However, there is not an accurate procedure to assuredly estimate this modulus by physical observation of the composite laminates. Ullah et al. [6] reported the flexural strength in the woven-fabric CFRP laminates $10 \%$ higher than tensile strength. They also investigated the nonlinear behavior of the laminates due to damage effects by cohesive zone elements. Regarding large capacity of the material under bending load in comparison with the tensile strength, the implemented designs based on the axial mechanical properties for the flexural structural components usually have acceptable safety factors. The difference of the flexural mechanical properties from tensile ones is not considered merely in the ultimate strength. Generally, the elastic modulus obtained by the bending test (flexural modulus) is different from that obtained by the tensile test. For many polymeric materials, the compressive stiffness is measured different from the tensile stiffness; the same subject shifts the neutral axis of the beam cross-section from the mid-height so that the flexural modulus becomes different from the tensile modulus. Jones [7] derived the elastic moduli for some composite laminates made of various materials under tension, compression, and three-point and four-point bending conditions and deduced that no clear pattern of larger tension than compression moduli or vice versa existed for fiberreinforced composite materials. Zweben et al. $[8,9]$ introduced the value of the flexural modulus lower than the tensile modulus for the unidirectional Kevlar 49/polyester composite beams. Tolf and Clarin [10] measured the flexural modulus $11 \%$ smaller than the tensile modulus for the E-glass/polyester specimens. Roopa et al. [11] reported the ratio of flexural to tensile modulus equal to 4 and 2.67 for glass/polyester and glass/vinylester specimens, respectively. It is noteworthy that flexural properties of the polymeric materials may vary with specimen depth, temperature, and the difference in rate of straining [12]. However, the main source of inconsistency in the estimation of the flexural response of the composite laminates seems to be inaccurate estimation of the material nonlinearity [13-16] or incorrect implementation of the contact conditions between supports and specimen.

The composite laminates are composed of two constituents: matrix and fibres. Most fibres have a linear elastic load carrying behavior without degradation of mechanical properties prior to failure; however, most matrices can undergo considerable nonlinear deformations before complete failure due to damage and plasticity. Therefore, it seems that the only method for accurate estimation of the load carrying capacity in the composite laminates under bending load will be achieved through Progressive Damage Analysis (PDA).
There are numerous progressive damage studies in the literature which have examined the failure performance of the composite laminates with various lay-up methods. Ochoa and Reddy [17] presented an excellent overview of the basic steps for performing a progressive failure analysis, which has been followed in numerous papers. Garnich and Akula [18] provided a brief summary of the major classes of failure criteria pertaining to the degradation models. Generally, the progressive damage studies investigate two main stages: first, initiation of damage in various modes of failure, which are characterized by interactive or non-interactive failure criteria, and second, damage evolution in each mode to accomplish complete failure. Soden et al. [19-21] presented a comprehensive comparison between the predictions of internationally recognized failure theories for fibre-reinforced polymer-composite laminates and showed similarities and differences between the predictions of various theories. Recently, progression of various pieces of $\mathrm{FE}$ software in the context of damage simulation has provided a unique opportunity for researchers to more accurately examine any damage effects on the performance of the composite laminates. Many researchers, by using FE tools, have performed progressive damage studies based on the micro/meso models for composite laminates with various lay-up methods [22-25]. Review of these researches shows that the majority of the progressive failure studies on the composite laminates were done under in-plane loading conditions and the examined cases under out-of-plane loads [26-29] were rarely compared.

The comparison between the flexural and tensile strengths shows clear insufficiency of the stress-based failure criteria to predict damage in the structures. Since the majority of the FRPs absorb energy by inelastic deformation and irreversible damages, the energy based damage criteria seem more appropriate candidates to predict failure in these materials [30-32]. Energy principles are preferable to strength criteria because they are determined based on the invariant properties of the materials [33,34]. The strain based failure criteria have also shown admissible accuracy in prediction of the ultimate strength in composite laminates under bending load [35]. Irhirane et al. [36] compared the numerical results obtained by various failure theories and showed that Hashin and HartSmith criteria were the best theories for prediction of the flexural failure in the composite laminates.

The objective of the present paper is prediction of the flexural strength of the composite laminated beams by the aid of Hashin failure criteria compared to the tensile strength of laminates. In the experimental program, the E-glass/vinylester composite laminates were tested under tensile and 3PB loads. First, the tensile response of the laminates was considered and the related FE models with progressive damage effects 
were verified. Then, the flexural behavior was simulated in some composite laminated beam specimens under 3PB conditions using numerical models. Useful explanations were presented to justify the difference between the flexural and tensile load carrying capacities of the composite laminates. To examine the influence of various stress components on the progression of the failure criteria, 3D solid elements were employed in the FE models. The failure criteria were implemented in a subroutine linked to the main program. The strain-based failure criteria could accurately estimate the ultimate load carrying capacity of the laminated beams rather than the stress-based criteria. The FE results could justify the difference of the maximum experienced stress measured under flexural and tensile loadings reasonably.

\section{Experiments}

Unidirectional plain weave E-glass fibres (weft fibres only for keeping the wrap fibers bonding) were utilized for fabrication of laminates with density of $400 \mathrm{gr} / \mathrm{m}^{2}$ and tensile strength of $600 \mathrm{MPa}$. The resin was vinylester with nominal tensile strength of $30 \mathrm{MPa}$. This resin is recommended when high chemical/environmental resistance is required for laminates. The fabrication process of the laminated plates was through the use of compact molding technique. The laminates were cured in $60^{\circ} \mathrm{C}$ temperature for $48 \mathrm{~h}$. On the exterior side of the laminates, usually, appropriate coating gels are used to protect the parts from weathering, moisture, and chemical exposure. In the provided laminates in this study, the thickness of the protecting blue-color gel was $0.1 \mathrm{~mm}$ of which the negligible influence on the measured mechanical properties was proven. The specimens with four lay-up methods were cut from the provided laminates. The experimental program consisted of tensile and $3 \mathrm{~PB}$ tests. The experiments were carried out at room temperature when the laminate density was $1800 \mathrm{~kg} / \mathrm{m}^{3}$. The tensile test setup is seen in Figure 1. The features of the specimens are observed in Table 1 according to the dimensions specified in Figure 2. Two strain gauges were attached to the specimen in longitudinal and transverse directions to measure Poisson's coefficient in the examined laminates. The provisions of ASTM 3039 standard [37] were applied in the tensile tests. All tests were conducted by a ZWICK machine under a displacement controlled-load when the crosshead velocity of the servo-hydraulic testing machine was $1 \mathrm{~mm} / \mathrm{min}$ for tensile tests and $5 \mathrm{~mm} / \mathrm{min}$ for $3 \mathrm{~PB}$ tests. The composite tabs were bonded to each head of the test coupons in order to prevent the gripping damage.

Selection of the span-to-depth ratio $(L / D)$ for beams plays a major role in accurate evaluation of

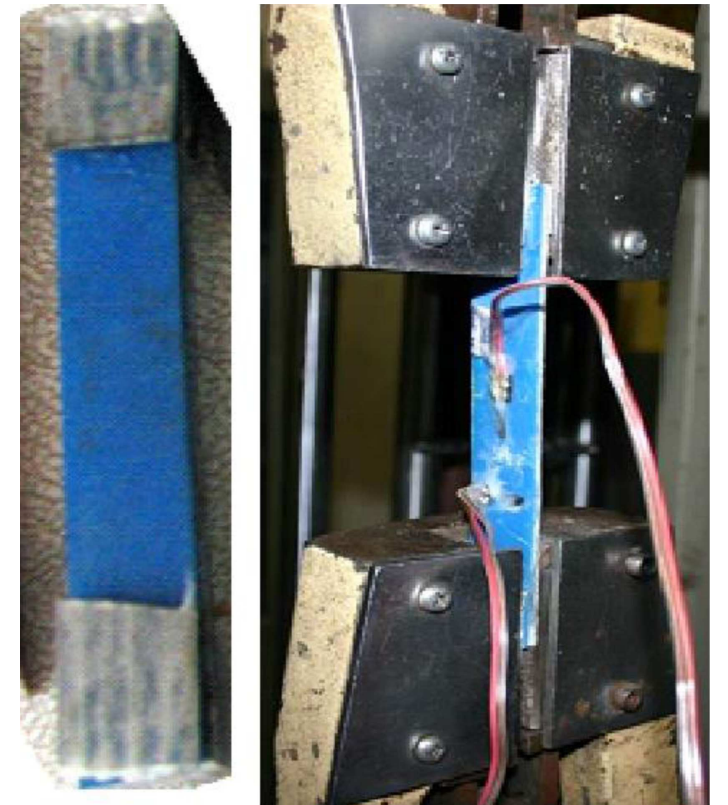

Figure 1. Test setup for tensile specimens.

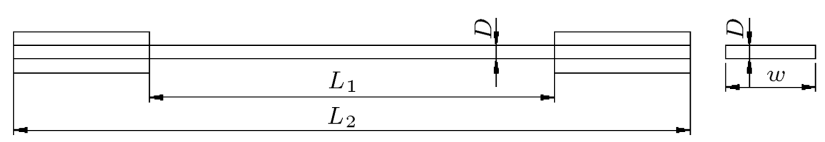

(a)

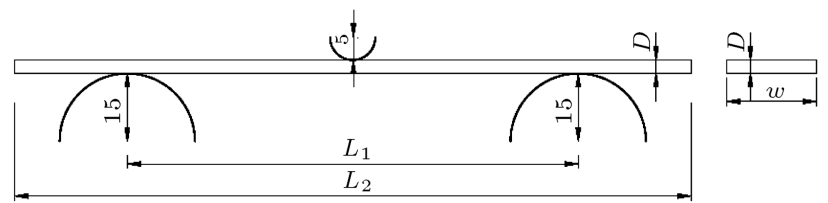

(b)

Figure 2. The dimensions denoted in Table 1 for (a) tensile specimens and (b) flexural specimens.

Table 1. The features of the specimens according to Figure 2 (dimensions with tolerance of $\pm 0.1 \mathrm{~mm}$ ).

\begin{tabular}{cccccc}
$\begin{array}{c}\text { Specimen } \\
\text { no. }\end{array}$ & $\boldsymbol{L}_{\mathbf{1}}$ & $\boldsymbol{L}_{\mathbf{2}}$ & $\boldsymbol{W}$ & $\boldsymbol{D}$ & Layup \\
\hline ST-1 & 100 & 151.2 & 20 & $4 \times 0.75$ & $(0)_{4}$ \\
ST-2 & 100 & 153.3 & 19.5 & $4 \times 0.75$ & $(90)_{4}$ \\
ST-3 & 100 & 153.5 & 19.6 & $4 \times 0.75$ & $\left(90,0_{3}\right)$ \\
ST-4 & 100 & 152.6 & 20.3 & $4 \times 0.75$ & $\left(0,90_{3}\right)$ \\
SF-1 & 100 & 150.4 & 19.4 & $4 \times 0.75$ & $(0)_{4}$ \\
SF-2 & 100 & 151.7 & 19.5 & $4 \times 0.75$ & $(90)_{4}$ \\
SF-3 & 100 & 151.3 & 20.7 & $4 \times 0.75$ & $\left(90,0_{3}\right)$ \\
SF-4 & 100 & 152.2 & 19.6 & $4 \times 0.75$ & $\left(0,90_{3}\right)$ \\
\hline
\end{tabular}

the flexural properties. The provisions of ASTM D790 [12] standard recommend that this ratio shall be selected such that the failure occurs in the outer fibres of the beams. It was mentioned that the value of the tensile modulus in the composite laminates was a unique value, which was determined by the standard tensile test. However, the flexural modulus could 
Table 2. Mechanical properties of the GFRP lamina (with tolerance of $\pm 10 \mathrm{MPa}$ ).

\begin{tabular}{cccccccccc}
\hline Properties & $\begin{array}{c}\boldsymbol{E}_{\mathbf{1}} \\
(\mathrm{MPa})\end{array}$ & $\begin{array}{c}\boldsymbol{E}_{\mathbf{2}} \\
(\mathrm{MPa})\end{array}$ & $\begin{array}{c}\boldsymbol{E}_{\mathbf{3}} \\
(\mathrm{MPa})\end{array}$ & $\boldsymbol{\nu}_{\mathbf{1 2}}$ & $\boldsymbol{\nu}_{\mathbf{1 3}}$ & $\boldsymbol{\nu}_{\mathbf{2 3}}$ & $\begin{array}{c}\boldsymbol{G}_{\mathbf{1 2}} \\
(\mathbf{M P a})\end{array}$ & $\begin{array}{c}\boldsymbol{G}_{\mathbf{1 3}} \\
(\mathbf{M P a})\end{array}$ & $\begin{array}{c}\boldsymbol{G}_{\mathbf{2 3}} \\
(\mathbf{M P a})\end{array}$ \\
\hline UD lamina & 12100 & 1420 & 1420 & 0.2 & 0.2 & 0.35 & 1070 & 1070 & 770 \\
\hline
\end{tabular}

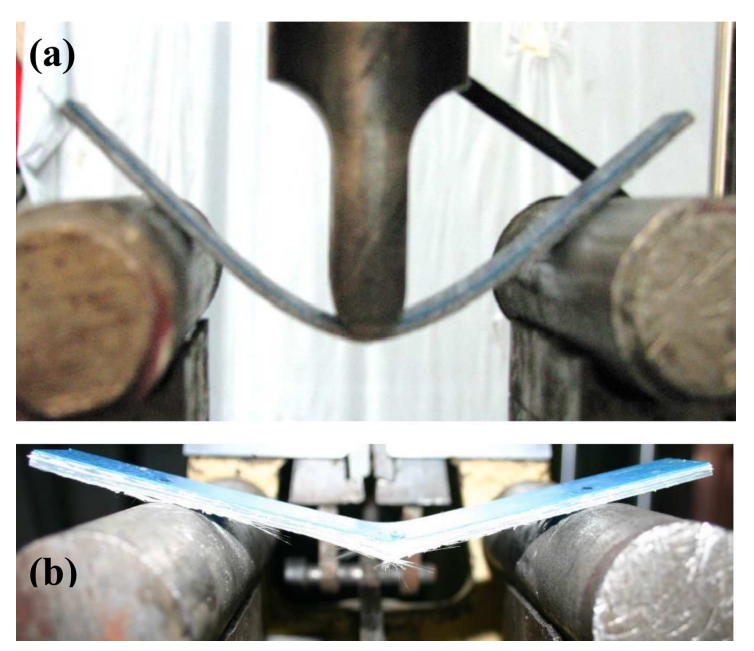

Figure 3. 3PB test of SF-1 specimen: (a) During load bearing when $\Delta=10 \mathrm{~mm}$, and (b) in the ultimate state with fibers rupture at the outer tensile side of the beam.

be dependent on the $L / D$ ratio of the tested beam. Also, ASTM D790 recommends the $L / D$ ratio of 32 for high orthotropic laminates. Thus, in this study, the $L / D$ ratio was selected equal to 33 for $3 \mathrm{~PB}$ test specimens. The number of specimens tested was 3 for each type to assure the reliability of the experimental results. The overhang length of the beam specimens was such that the specimens remained in permanent contact with supports via large deflections. Figure 3(a) shows a typical beam specimen during the load bearing and Figure 3(b) shows failure shape of SF-2 specimen after test. In the ASTM D790 standard, the flexural modulus by $3 \mathrm{~PB}$ test is derived from:

$$
E_{B}=L^{3} m / 4 b d^{3},
$$

where $E_{B}$ is the modulus of elasticity in bending, $L$ is supported span, $b$ and $d$ are the width and depth of beam, respectively, and $m$ is the slope of the tangent to the initial straight-line portion of the load-deflection curve. Also, the stress on the outer surface of the specimen can be reasonably approximated by:

$$
\sigma_{f}=\left(3 P L / 2 b d^{2}\right)\left[1+6(D / L)^{2}-4(d / L)(D / L)\right]
$$

where $\sigma$ is the stress in the outer fibers at midpoint; $P$ is load at a given point on the load-deflection curve; $D$ is deflection of the centreline of the specimen in the middle of the support span; and $L, b$, and $d$ are same as in Eq. (1). ASTM implies that the accuracy of the preceding calculations will decrease if the specimen slips excessively on the supports due to large deflections.

\section{FE modeling procedure}

FE simulation of the experimental specimens was carried out in order to describe the progressive failure in the composite beams step by step prior to the ultimate state. The FE software for modeling of the specimens was Abaqus. Both types of specimens, i.e., tensile and bending, were modelled using eightnode solid elements while the supports and the loading device were simulated by rigid shell elements. The FE model of the tensile specimens was considered between two rigid plates in lieu of the grips and the boundary conditions were applied to these plates. The unidirectional velocity load was applied to the top rigid plate when the bottom one was fixed. The Degrees Of Freedom (DOFs) in the two ends of the specimen were constrained to DOFs of the rigid plates using "Tie" constraint in Abaqus. Regarding the symmetry of the composite beam, only one half of the beams was modelled while the appropriate boundary conditions were employed for symmetry surface. The contact between the specimen and the supports was defined in both normal and tangential directions with a proper friction coefficient to control sliding of the specimen on the supports at loading. By physical evaluation of the surface roughness, the friction coefficient for the contact surfaces of the rollers and specimens was assumed equal to $\mu=0.3$. Batra et al. [38] assumed $\mu=0.25$ for this coefficient in determining of contact between composite beams and supports.

The failure of the composite laminates was considered based on Continuum Damage Mechanics (CDM) theory. In this theory, at each integration point of the elements, a framework that accounts for the stiffness degradation of the material is aimed at. For this purpose, "VUSDFLD" subroutine was utilized and linked to the main program. This subroutine determines the material mechanical properties dependent on the predetermined updating damage variables. The damage evolution process is explained in the following sections. Explicit dynamic analysis was chosen to investigate the progressive damage in the beams.

According to the experiments, the unidirectional velocity load was assigned to the loading nose. For each model, the mesh convergence study was done in order to select the sufficient and optimized dimensions for mesh. Table 2 gives the mechanical properties of 
the GFRP layers as $E_{1}, E_{2}$, and $E_{3}$ for the modulus in the longitudinal (local 1 ) and transverse (locals 2 and 3) directions, respectively; $\nu_{12}, \nu_{13}$, and $\nu_{23}$ for Poisson coefficient in the local 1-2, 1-3, and 2-3 planes; and $G_{12}, G_{13}$, and $G_{23}$ for shear modulus in $1-2,1-3$, and 2-3 planes, respectively.

\subsection{Progressive damage model}

Based on CDM theory, the damaged state of the material is related to its intact state by applying some damage variables to degrade the material mechanical properties. Abaqus [39] proposed a PDA (progressive damage analysis) model established on the decohesive element proposed by Camanho and Davila [40] in combination with Hashin damage initiation criteria [41,42]. This procedure has been utilized in many researches for investigation into the progressive damage in composite materials $[43,44]$. The first subject for investigation into damage is determination of the failure initiation time by the aid of appropriate failure criteria. In the present research, the failure criteria utilized for investigation into the failure of the laminated beams were established based on the theory proposed by Hashin and Rotem in the form of strain and stress components. In the FE models, progressive damage was activated by initiation of one failure mode followed by degradation of the elements stiffness due to increase in the load. The failure modes investigated in the composite laminates are:

- Fibers rupture in tension $\left(f_{1}\right)$;

- Fibers buckling and kinking in compression $\left(f_{2}\right)$;

- Matrix cracking under transverse tension and shearing in local 2 and 3 directions $\left(f_{3}\right)$;

- Matrix crushing under transverse compression and shearing in local 2 and 3 directions $\left(f_{4}\right)$.

On the basis of these modes, four damage criteria were introduced to check the damage probability in the composite elements when they were respectively violated as:

$$
\begin{aligned}
& f_{1}=\left(\frac{\sigma_{11}}{\sigma_{f}^{t}}\right)^{2}+\frac{\tau_{12}^{2}+\tau_{13}^{2}}{\left(\tau_{l}^{s}\right)^{2}} \leq 1, \quad \varepsilon_{11} \geq 0 \\
& f_{2}=\left(\frac{\sigma_{11}}{\sigma_{f}^{c}}\right)^{2} \leq 1, \\
& f_{3}=\left(\frac{\sigma_{22}+\sigma_{33}}{\sigma_{m}^{t}}\right)^{2}+\frac{\tau_{12}^{2}+\tau_{13}^{2}}{\left(\tau_{l}^{s}\right)^{2}}+\frac{\tau_{23}^{2}-\sigma_{22} \sigma_{33}}{\left(\tau_{t}^{s}\right)^{2}} \leq 1 \\
& \varepsilon_{22}+\varepsilon_{33} \geq 0
\end{aligned}
$$

$$
\begin{aligned}
f_{4}= & \left(\frac{\sigma_{22}+\sigma_{33}}{2 \tau_{t}^{s}}\right)^{2}+\frac{\sigma_{22}+\sigma_{33}}{\sigma_{m}^{c}} \cdot\left[\left(\frac{Y^{C}}{2 \tau_{t}^{s}}\right)^{2}-1\right] \\
& +\frac{\tau_{12}^{2}+\tau_{13}^{2}}{\left(\tau_{l}^{s}\right)^{2}}+\frac{\tau_{23}^{2}-\sigma_{22} \sigma_{33}}{\left(\tau_{t}^{s}\right)^{2}} \leq 1, \\
\sigma_{22} & +\sigma_{33}<0 .
\end{aligned}
$$

In the above formulae, $\sigma_{i j}$ are the stress components in 3D elements, $\sigma_{f}^{t}$ and $\sigma_{m}^{t}$ are tensile failure initiation stresses in the fibre and transverse directions, respectively, $\sigma_{f}^{c}$ and $\sigma_{m}^{c}$ are compressive failure initiation stresses in the fibre and transverse directions, respectively, and $\tau_{l}^{s}$ is the shear failure initiation stress in the longitudinal direction (1-2 and 1-3) when $\tau_{t}^{s}$ is the shear failure initiation stress in the transverse direction (23 ). It is obvious that the Hashin failure criteria prior to damage initiation can be rewritten based on the strain components as:

$$
\begin{aligned}
f_{1}= & \left(\frac{\varepsilon_{11}}{\varepsilon_{f}^{t}}\right)^{2}+\frac{\varepsilon_{12}^{2}+\varepsilon_{13}^{2}}{\left(\varepsilon_{l}^{s}\right)^{2}} \leq 1, \quad \varepsilon_{11} \geq 0 \\
f_{2}= & \left(\frac{\varepsilon_{11}}{\varepsilon_{f}^{c}}\right)^{2} \leq 1 \\
f_{3}= & \left(\frac{\varepsilon_{22}+\varepsilon_{33}}{\varepsilon_{m}^{t}}\right)^{2}+\frac{\varepsilon_{12}^{2}+\varepsilon_{13}^{2}}{\left(\varepsilon_{l}^{s}\right)^{2}}+\frac{\varepsilon_{23}^{2}-\varepsilon_{22} \varepsilon_{33}}{\left(\varepsilon_{t}^{s}\right)^{2}} \leq 1 \\
\varepsilon_{22} & +\varepsilon_{33} \geq 0, \\
f_{4}= & \left(\frac{\varepsilon_{22}+\varepsilon_{33}}{2 \varepsilon_{s}^{t}}\right)^{2}+\frac{\varepsilon_{22}+\varepsilon_{33}}{\varepsilon_{m}^{c}} .\left[\left(\frac{\varepsilon_{m}^{c}}{2 \varepsilon_{t}^{s}}\right)^{2}-1\right] \\
& +\frac{\varepsilon_{12}^{2}+\varepsilon_{13}^{2}}{\left(\varepsilon_{l}^{s}\right)^{2}}+\frac{\varepsilon_{23}^{2}-\varepsilon_{22} \varepsilon_{33}}{\left(\varepsilon_{t}^{s}\right)^{2}} \leq 1 \\
\varepsilon_{22} & +\varepsilon_{33}<0,
\end{aligned}
$$

where $\varepsilon_{i j}$ are the strain components in $3 \mathrm{D}$ elements, $\varepsilon_{f}^{t}$ and $\varepsilon_{m}^{t}$ are tensile failure initiation strains in the fibre and transverse directions, respectively, $\varepsilon_{f}^{c}$ and $\varepsilon_{m}^{c}$ are compressive failure initiation strains in the fibre and transverse directions, respectively, and $\varepsilon_{l}^{s}$ is the shear failure initiation strain in the longitudinal direction (12 and 1-3) when $\varepsilon_{t}^{s}$ is the shear failure initiation strain in the transverse direction (2-3). The above-mentioned criteria include the effects of three-dimensional stresses through the Poisson coefficient. The effective stresses are obtained by multiplication of the nominal stresses to the damage matrix as [45]:

$$
\widehat{\sigma}=\mathbf{M} \sigma
$$

where $\mathbf{M}$ is a diagonal matrix of the damage operators as: 


$$
\begin{array}{r}
\mathbf{M}=\left[\begin{array}{ccc}
1 /\left(1-d_{f}\right) & 0 & 0 \\
0 & 1 /\left(1-d_{m}\right) & 0 \\
0 & 0 & 1 /\left(1-d_{m}\right) \\
0 & 0 & 0 \\
0 & 0 & 0 \\
0 & 0 & 0 \\
0 & 0 & 0 \\
0 & 0 & 0 \\
0 & 0 & 0 \\
1 /\left(1-d_{l}^{s}\right) & 0 & 0 \\
0 & 1 /\left(1-d_{l}^{s}\right) & 0 \\
0 & 0 & 1 /\left(1-d_{t}^{s}\right)
\end{array}\right]
\end{array}
$$

In this matrix, $d_{f}, d_{m}, d_{l}^{s}$, and $d_{t}^{s}$ are damage variables for fibres, matrix, longitudinal shear, and transverse shear failure modes, respectively. The damage variables corresponding to shear, namely, $d_{l}^{s}$ and $d_{t}^{s}$, are assumed to be functions of the other variables. Since the majority of the composite laminates have different failure performances under tensile and compressive loads, the damage variables $d_{f}$ and $d_{m}$ are distinguished for tension and compression performances by subscripts $t$ and $c$ as [39]:

$$
\begin{aligned}
& d_{f}= \begin{cases}d_{f}^{t} & \text { if } \varepsilon_{11} \geq 0 \\
d_{f}^{c} & \text { if } \varepsilon_{11}<0\end{cases} \\
& d_{m}= \begin{cases}d_{m}^{t} & \text { if }\left(\varepsilon_{22}+\varepsilon_{33}\right) \geq 0 \\
d_{m}^{c} & \text { if }\left(\varepsilon_{22}+\varepsilon_{33}\right)<0\end{cases} \\
& d_{s}^{l}=1-\left(1-d_{f}^{t}\right)\left(1-d_{f}^{c}\right)\left(1-d_{m}^{t}\right)\left(1-d_{m}^{c}\right), \\
& d_{s}^{t}=1-\left(1-d_{m}^{t}\right)^{2}\left(1-d_{m}^{c}\right)^{2} .
\end{aligned}
$$

The complementary free energy density in the material is calculated as [45]:

$$
\begin{aligned}
G= & \frac{1}{2 E_{1}}\left(\frac{\left\langle\sigma_{11}\right\rangle^{2}}{1-d_{f}^{t}}+\frac{\left\langle-\sigma_{11}\right\rangle^{2}}{1-d_{f}^{t}}\right) \\
& +\frac{1}{2 E_{2}}\left(\frac{\left\langle\sigma_{22}\right\rangle^{2}}{1-d_{m}^{t}}+\frac{\left\langle-\sigma_{22}\right\rangle^{2}}{1-d_{m}^{c}}\right) \\
& +\frac{1}{2 E_{3}}\left(\frac{\left\langle\sigma_{33}\right\rangle^{2}}{1-d_{m}^{t}}+\frac{\left\langle-\sigma_{33}\right\rangle^{2}}{1-d_{m}^{c}}\right) \\
& -\frac{\nu_{12} \sigma_{11} \sigma_{22}}{E_{1}}-\frac{\nu_{13} \sigma_{11} \sigma_{33}}{E_{1}}-\frac{\nu_{23} \sigma_{22} \sigma_{33}}{E_{2}} \\
& +\frac{\sigma_{12}^{2}}{G_{12}\left(1-d_{l}^{s}\right)}+\frac{\sigma_{13}^{2}}{G_{13}\left(1-d_{l}^{s}\right)}+\frac{\sigma_{23}^{2}}{G_{23}\left(1-d_{t}^{s}\right)} .
\end{aligned}
$$

To ensure thermodynamical irreversibility of the damage process, the rate of change of the complementary free energy, $\dot{G}$, minus the externally supplied work to the solid at constant strains $\dot{\sigma}: \varepsilon$ must be non-negative:

$$
\dot{G}-\dot{\sigma}: \varepsilon \geq 0 \text {. }
$$

Expanding the inequality in terms of stress tensor and damage variables gives:

$$
\begin{aligned}
\left(\frac{\partial G_{\mathrm{eq}}}{\partial \sigma}-\varepsilon\right): \dot{\sigma} & +\frac{\partial G_{\mathrm{eq}}}{\partial d_{f}} \dot{d}_{f}+\frac{\partial G_{\mathrm{eq}}}{\partial d_{m}} \dot{d}_{m}+\frac{\partial G_{\mathrm{eq}}}{\partial d_{l}} \dot{d}_{l}^{s} \\
& +\frac{\partial G_{\mathrm{eq}}}{\partial d_{t}} \dot{d}_{t}^{s} \geq 0
\end{aligned}
$$

Since the stresses are variables, the expression in the parenthesis must be equal to zero to ensure positive dissipation of mechanical energy [45]:

$$
\begin{aligned}
\varepsilon & =\frac{\partial G}{\partial \sigma}=\mathbf{H}: \sigma, \\
\sigma & =\mathbf{C}_{\mathbf{d}} \varepsilon .
\end{aligned}
$$

$\mathbf{H}$ is the flexibility matrix and $\mathbf{C}_{\mathbf{d}}$ is the damaged stiffness matrix. Using the above relation and the quantitative assessments for degradation of the Poisson's coefficients, the elements of the degraded stiffness matrix are obtained as presented in Appendix A. By separating the influence of complementary free energy in various modes of failure, an equivalent energy $\left(G_{\text {eq }}\right)$ for each mentioned mode is established for investigation into the damage evolution in the elements. The equivalent energies are defined equal to the area under the equivalent stress versus the equivalent displacement diagram (see Figure 4), while the next two parameters are determined by considering the characteristic length $\left(L^{C}\right)$ for the elements [39] as:

$$
\begin{aligned}
& \delta_{\text {eq }}^{f t}=L^{C} \sqrt{\left\langle\varepsilon_{11}\right\rangle^{2}+\varepsilon_{12}^{2}+\varepsilon_{13}^{2}}, \\
& \sigma_{\text {eq }}^{f t}=\frac{\left\langle\sigma_{11}\right\rangle\left\langle\varepsilon_{11}\right\rangle+\tau_{12} \varepsilon_{12}+\tau_{13} \varepsilon_{13}}{\delta_{\text {eq }}^{f t} / L^{C}},
\end{aligned}
$$

for fibres tension $\left(\sigma_{11} \geq 0\right)$ :

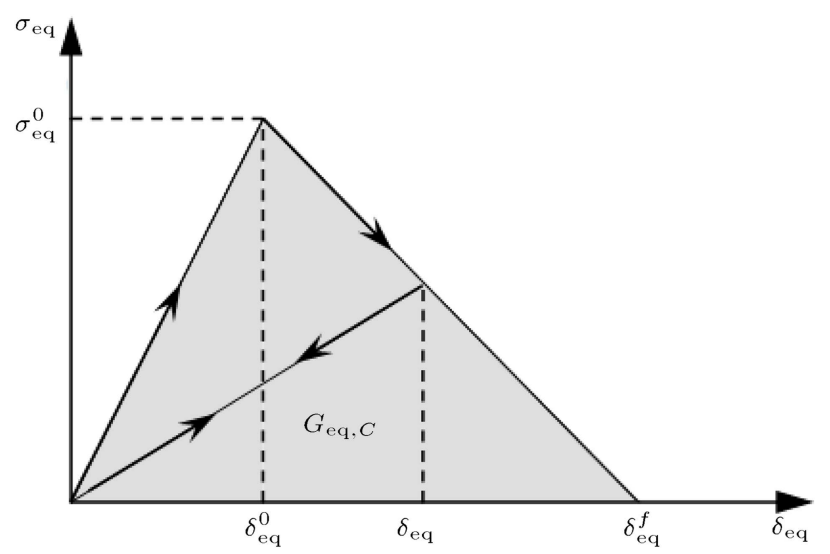

Figure 4. Schematic of equivalent stress versus equivalent displacement diagram [39]. 


$$
\begin{aligned}
& \delta_{\mathrm{eq}}^{f c}=L^{C}\left\langle-\varepsilon_{11}\right\rangle, \\
& \sigma_{\mathrm{eq}}^{f c}=\frac{\left\langle-\sigma_{11}\right\rangle\left\langle-\varepsilon_{11}\right\rangle}{\delta_{\mathrm{eq}}^{f t} / L^{C}},
\end{aligned}
$$

for fibers compression $\left(\sigma_{11}<0\right)$ :

$$
\begin{aligned}
& \delta_{\mathrm{eq}}^{m t}=L^{C} \sqrt{\left\langle\varepsilon_{22}+\varepsilon_{33}\right\rangle^{2}+\left(\varepsilon_{12}^{2}+\varepsilon_{13}^{2}\right)} \\
& \sigma_{\mathrm{eq}}^{m t}=\frac{\left\langle\sigma_{22}\right\rangle\left\langle\varepsilon_{22}\right\rangle+\left\langle\sigma_{33}\right\rangle\left\langle\varepsilon_{33}\right\rangle+\tau_{12} \varepsilon_{12}+\tau_{13} \varepsilon_{13}}{\delta_{\mathrm{eq}}^{m t} / L^{C}}
\end{aligned}
$$

for matrix tension and shear $\left(\sigma_{22}+\sigma_{33}>0\right)$ :

$$
\begin{aligned}
& \delta_{\mathrm{eq}}^{m c}=L^{C} \sqrt{\left.\left\langle-\left(\varepsilon_{22}+\varepsilon_{33}\right)\right\rangle^{2}+\varepsilon_{12}^{2}+\varepsilon_{13}^{2}\right)}, \\
& \sigma_{\mathrm{eq}}^{m c}=\frac{\left\langle-\left(\sigma_{22}+\sigma_{33}\right)\right\rangle\left\langle-\left(\varepsilon_{22}+\varepsilon_{33}\right)\right\rangle+\tau_{12} \varepsilon_{12}+\tau_{13} \varepsilon_{13}}{\delta_{\mathrm{eq}}^{m c} / L^{C}},
\end{aligned}
$$

and for matrix compression $\left(\sigma_{22}+\sigma_{33}<0\right)$, where $<>$ is a Macaulay bracket operator defined for every $\omega \epsilon R$ as $\langle\omega\rangle=(\omega+|\omega|) / 2$. Since the dissipated energy is proportional to the volume of the elements, it varies with mesh refinement. Therefore, the equivalent energies $\left(G_{\text {eq }}{ }^{s}\right)$ are normalized regarding a characteristic length for the elements, $L^{C}$, which is defined by Bazant and $\mathrm{Oh}$ [46] for brick elements as:

$$
L^{C}=\sqrt[3]{V_{e l}}
$$

where $V_{e l}$ is volume of the element. The damage variable associated with each failure mode $i$ takes values between zero (undamaged state) and one (fully damaged state) as [47]:

$d_{j}^{i}=\frac{\left(\delta_{j, \mathrm{eq}}^{i}\right)^{u}\left(\delta_{j, \mathrm{eq}}^{i}-\left(\delta_{j, \mathrm{eq}}^{i}\right)^{0}\right)}{\delta_{j, \mathrm{eq}}^{i}\left(\left(\delta_{j, \mathrm{eq}}^{i}\right)^{u}-\left(\delta_{j, \mathrm{eq}}^{i}\right)^{0}\right)}, \quad i=t, c, \quad$ and $\quad j=\underset{(27)}{f}, \mathrm{~s}$.

Using Table $3,\left(\delta_{j, \text { eq }}^{i}\right)^{0}$ were derived from strains in which damage was initiated, $\left(\delta_{j \text {,eq }}^{i}\right)^{u}$ were derived from strains in which damage was completed, and $\delta_{j \text {,eq }}^{i}$ were derived by the available strains in the material during the load carrying after initiation of damage. When the stress-based failure criteria were utilized, the stress based damage variables for each failure mode $i$ were derived from:

$d_{j}^{i}=\frac{\left(\sigma_{j, \mathrm{eq}}^{i}\right)^{u}\left(\sigma_{j, \mathrm{eq}}^{i}-\left(\sigma_{j, \mathrm{eq}}^{i}\right)^{0}\right)}{\sigma_{j, \mathrm{eq}}^{i}\left(\left(\sigma_{j, \mathrm{eq}}^{i}\right)^{u}-\left(\sigma_{j, \mathrm{eq}}^{i}\right)^{0}\right)}, \quad i=t, c$, and $j=\underset{f, m}{f}$.

Using Table $3,\left(\sigma_{j \text {,eq }}^{i}\right)^{0}$ were derived by stresses in which damage was initiated, $\left(\sigma_{j \text {, eq }}^{i}\right)^{u}$ were derived by stresses in which damage was completed, and $\sigma_{j \text {,eq }}^{i}$ were derived by the available stresses in the material during the load carrying time after initiation of damage.

\section{Results and discussion}

Investigation into the load carrying capacity in composite laminates without consideration of progressive damage in the models reduces the accuracy of the results, especially when substantial nonlinearity is noticed prior to ultimate strength. In the following sections, first, the utilized damage models are verified by the results of the tension tests. Then, the flexural performance of $3 \mathrm{~PB}$ beams is simulated to consider the maximum stress experienced by the laminates under bending load.

\subsection{Load carrying under tension}

Both experimental and FE stress-strain curves obtained from all specimens are depicted in Figure 5. The mesh convergence study showed that assignment of one element per layer for FE models of the tensile specimens could achieve accurate results. Figure 6 shows the FE model of ST-1 specimen prior to the failure state. The stiffness of UD lamina in the fibre direction did not show any degradation prior to rupture state, but in the transverse direction, a gradual material degradation progress was observed. It must be noted that the damage evolution protocol was assumed identical for simulation of the tensile and bending specimens.

Table 3. Ultimate strains and stresses of examined GFRP lamina (with tolerance of \pm 0.001 for strains).

\begin{tabular}{cccccc}
\hline Properties & UD lamina & Properties & UD lamina & Properties & UD lamina \\
\hline$\left(\epsilon_{f}^{t}\right)^{0}$ & 0.029 & $\left(\epsilon_{l}^{s}\right)^{0}$ & 0.0019 & $\left(\sigma_{f}^{c}\right)^{0}$ & 345 \\
$\left(\epsilon_{f}^{t}\right)^{u}$ & 0.029 & $\left(\epsilon_{l}^{s}\right)^{u}$ & 0.037 & $\left(\sigma_{f}^{c}\right)^{u}$ & 345 \\
$\left(\epsilon_{m}^{t}\right)^{0}$ & 0.0013 & $\left(\epsilon_{t}^{s}\right)^{0}$ & 0.0022 & $\left(\sigma_{m}^{c}\right)^{0}$ & 3 \\
$\left(\epsilon_{m}^{t}\right)^{u}$ & 0.0255 & $\left(\epsilon_{t}^{s}\right)^{u}$ & 0.043 & $\left(\sigma_{m}^{c}\right)^{u}$ & 51 \\
$\left(\epsilon_{f}^{c}\right)^{0}$ & 0.032 & $\left(\sigma_{f}^{t}\right)^{0}$ & 345 & $\left(\tau_{l}^{s}\right)^{0}$ & 2 \\
$\left(\epsilon_{f}^{c}\right)^{u}$ & 0.032 & $\left(\sigma_{f}^{t}\right)^{u}$ & 345 & $\left(\tau_{l}^{s}\right)^{u}$ & 40 \\
$\left(\epsilon_{m}^{c}\right)^{0}$ & 0.002 & $\left(\sigma_{m}^{t}\right)^{0}$ & 2 & $\left(\tau_{t}^{s}\right)^{0}$ & 1.7 \\
$\left(\epsilon_{m}^{c}\right)^{u}$ & 0.065 & $\left(\sigma_{m}^{t}\right)^{u}$ & 38 & $\left(\tau_{t}^{s}\right)^{u}$ & 33 \\
\hline
\end{tabular}




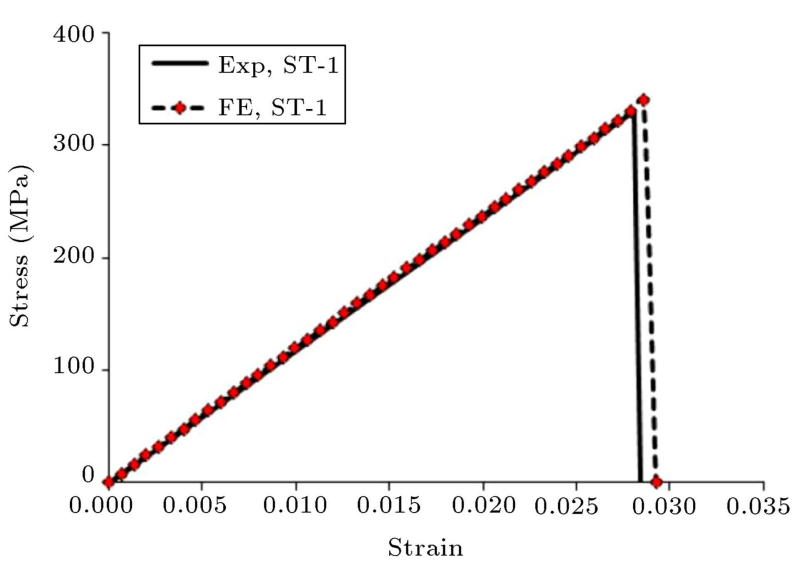

(a)

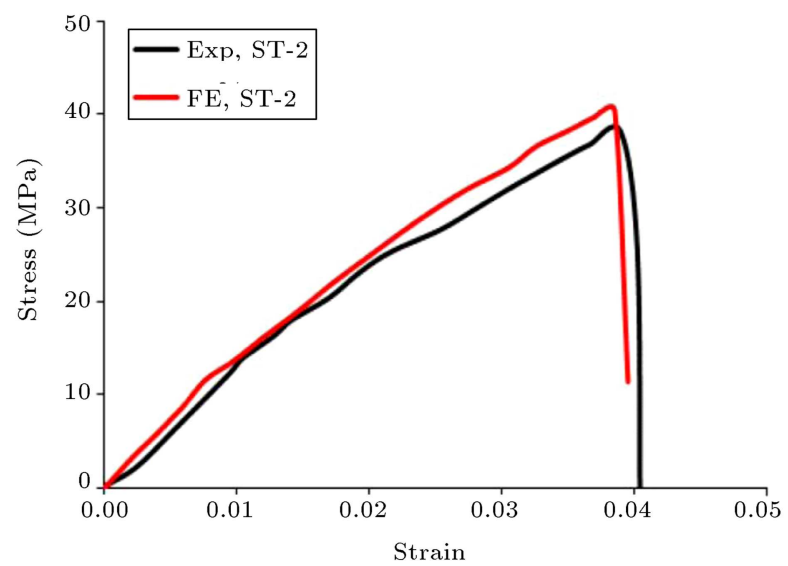

(b)

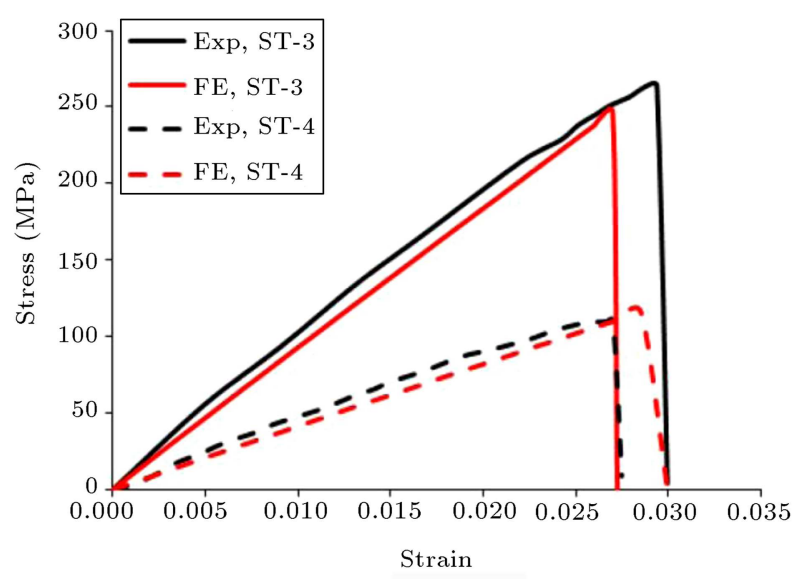

(c)

Figure 5. Stress-strain graphs obtained by experiment and FE simulation of the tensile specimens: (a) ST-1, (b) ST-2, and (c) ST-3 and ST-4.

\subsection{Load carrying under bending}

\subsubsection{Mesh convergence study}

A numerical study showed that the mesh size of the FE models considerably influenced the accuracy of the FE models in predicting the flexural strength. The mesh convergence study was carried out in two steps. In the first step, having equal mesh dimensions on the

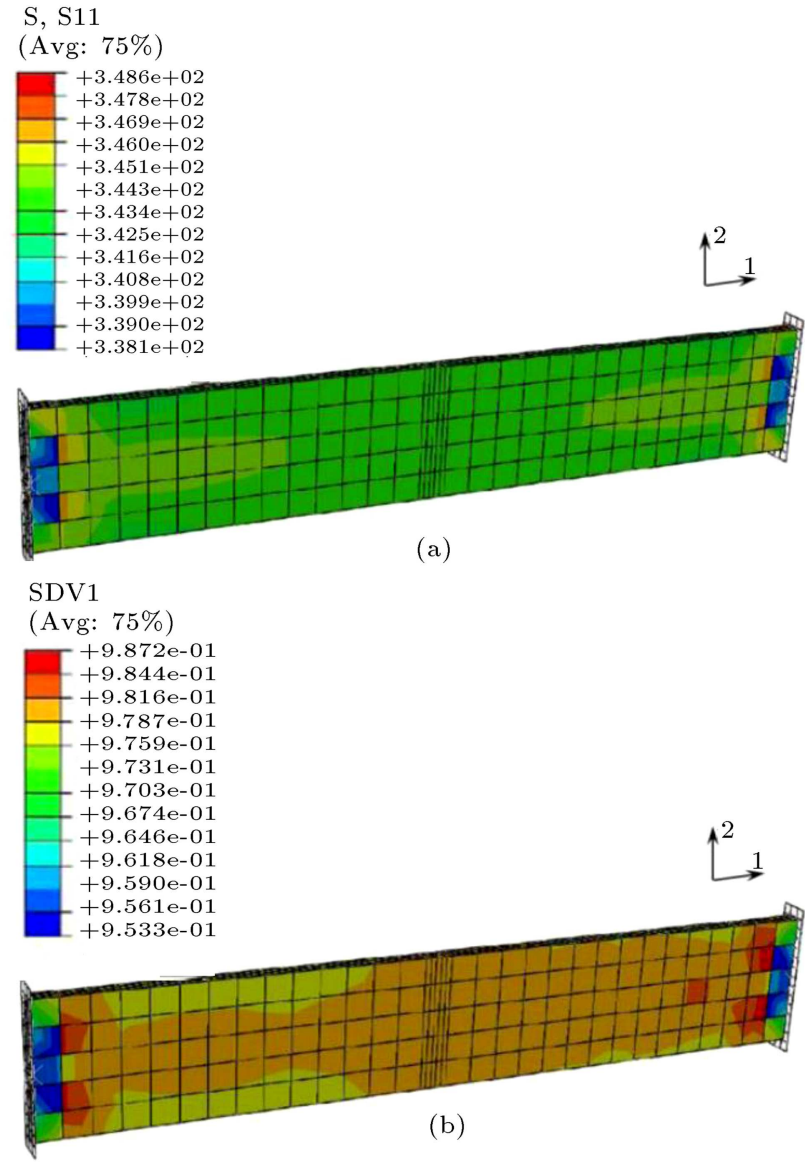

Figure 6. (a) Longitudinal stress distribution in the FE model of the ST-1 specimen prior to rupture state. (b) $f_{1}$ criteria (Eq. (7)) in the same time.

top surface of the beam, various numbers of elements were assigned to the thickness of the beam while in the second step, with different numbers of elements for the thickness, various mesh schemes were considered on the surface of the FE models according to Table 4. In Figure 7(a), the load-deflection curves belong to different numbers of elements in the thickness of SF1 beam with the second type of grid on the surface as shown in Table 4. According to these curves, the model with two elements in the thickness could not represent the actual failure at the ultimate state and sudden decrease in the curve of this model was observed due to considerable sliding of the beam on the supports following large deflection of the beam. Figure $7(\mathrm{~b})$ shows the load-deflection curves of three mesh schemes presented in Table 4 while the number of elements in the thickness of the beam was 4 . This figure shows that the dimension of the mesh on the top surface of the beam is less pronounced in the accuracy of the results. Figure 8 compares the running times of the FE models with various numbers of elements in the thickness with respect to the model with two elements in the thickness. These analyses have been carried out by an identical processing computer. 
Table 4. Various mesh dimensions (mm) applied to the surface of SF-1 specimen for mesh convergence study.

\begin{tabular}{lccc}
\hline Mesh plans in surface of beam & Plan 1 & Plan 2 & Plan 3 \\
\hline General mesh size & $2.5 \times 2.5$ & $5 \times 5$ & $10 \times 6.67$ \\
Mesh size around the mid-span & $1 \times 2.5$ & $1.67 \times 5$ & $2 \times 6.67$ \\
\hline
\end{tabular}

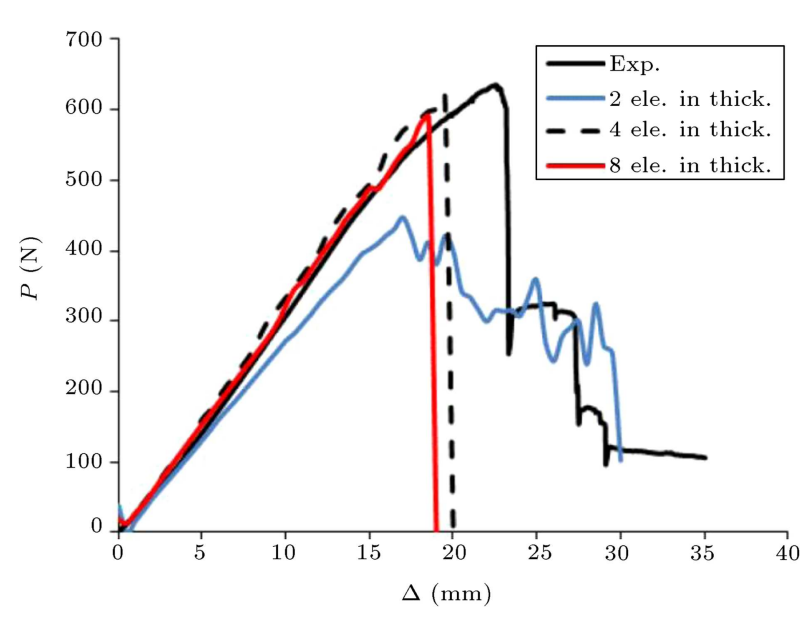

(a)

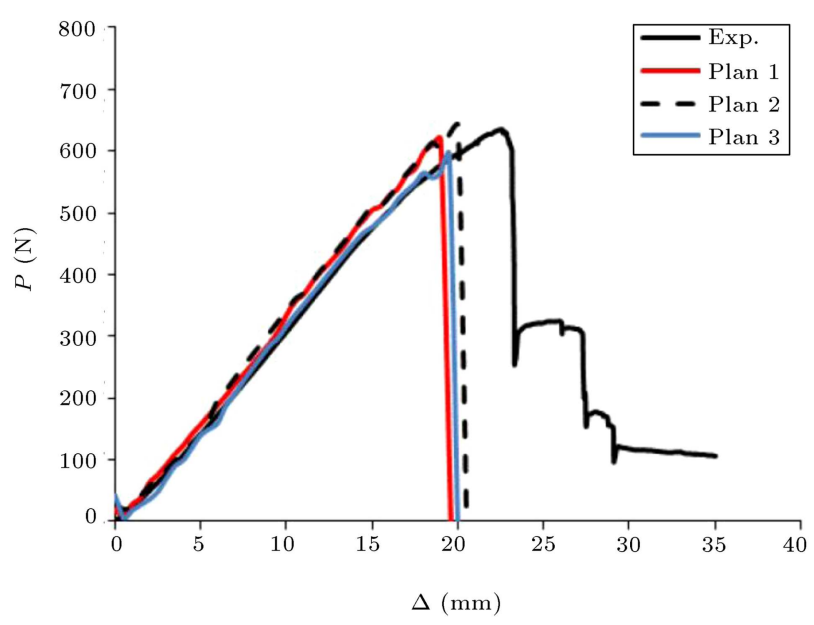

(b)

Figure 7. Mesh convergence study of SF-1 specimen: (a) Influence of various numbers of elements in the thickness, and (b) influence of various mesh dimensions in the beam surface according to Table 4 .

\subsubsection{Performance of UD laminates}

Four elements were assigned to the thickness of the FE model for SF-1 specimen. The second meshing plan presented in Table 4 was utilized for mesh of the beam surface. Assigning of finer elements around the beam mid-span was due to the larger deformation gradient in this area. In Figure 9, the load-deflection curves obtained from the experimental and numerical studies for SF-1 specimen are seen. In the loaddeflection curve presented in this study, $P$ and $\Delta$ denote the applied load and the mid-span deflection,

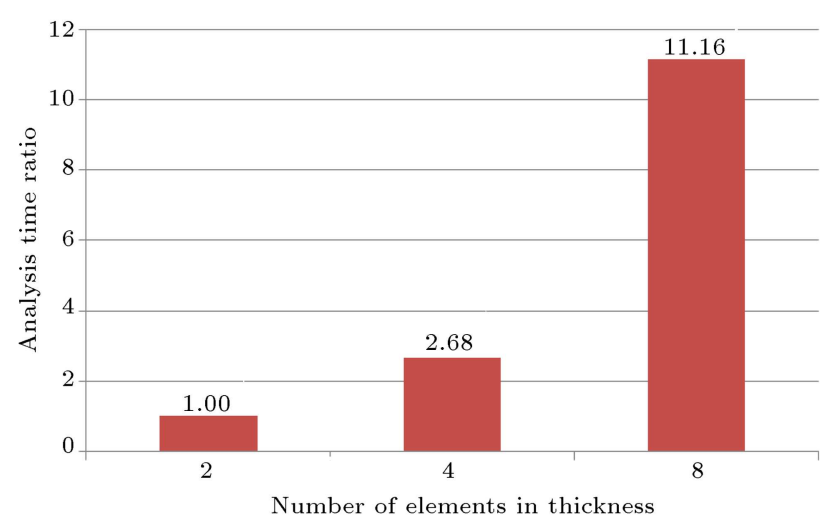

Figure 8. Comparison of analysis times spent for the FE model of SF-1 specimen with various numbers of elements in the thickness.

respectively. Eq. (1) gives the value of the flexural modulus equal to $13600 \mathrm{MPa}$ for SF-1 specimen. The FE model gave more accurate results when the modulus of elasticity was taken equal to $E=13000 \mathrm{MPa}(7.4 \%$ larger than the tensile modulus). There is a large discrepancy between the ultimate strength obtained by Eq. (2) and reality. Table 5 shows that the maximum experienced stress by the FE model of SF-1 specimen is $400 \mathrm{MPa}(16 \%$ higher than the ultimate tensile strength). Figure 10 shows stress in the fibre direction prior to crack detection and, then, the failure of the elements in the beam mid-span, which leads to the collapse of the load deflection curve. Value of 1 for $f_{1}$ denotes fibres tensile rupture in the beam. The results of FE model (seen in Figure 9) based on the maximum stress theory showed that if the maximum allowable stress was $345 \mathrm{MPa}$, the ultimate load for this specimen would be underestimated. The strain-based failure criteria indicate that when the modulus of elasticity increases under bending load relative to the tensile modulus, the ultimate strength increases to reach ultimate strain under bending loads. The load-deflection curve shows that the ultimate strain for occurrence of flexural failure in the SF-1 specimen is slightly smaller than that seen in the tensile failure. Physical observations during loading showed that the failure of the UD laminated beams did not occur unless the whole tensile part of the section ruptured, simultaneously. Wisnom and Atkinson [48] showed that flexural failure of unidirectional carbon fibre/epoxy was usually a gradual process, with bundles of fibres breaking first at the surface and, then, progressively through the 


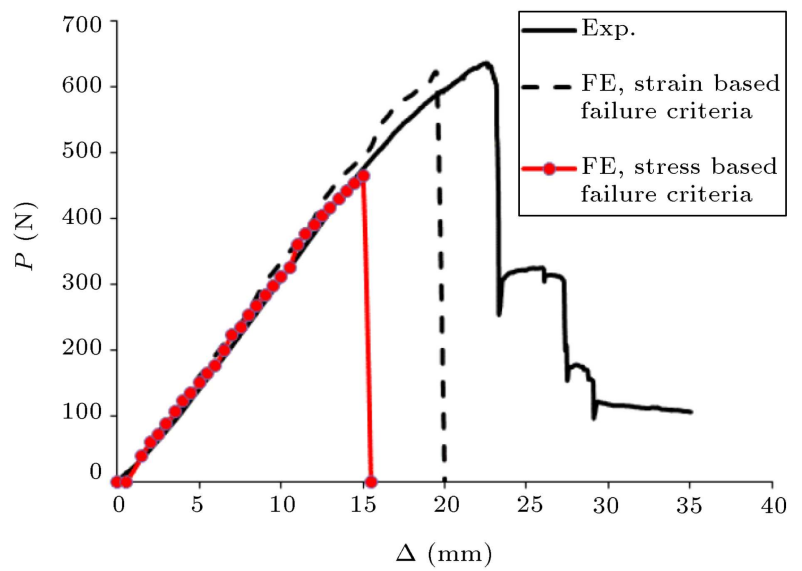

(a)

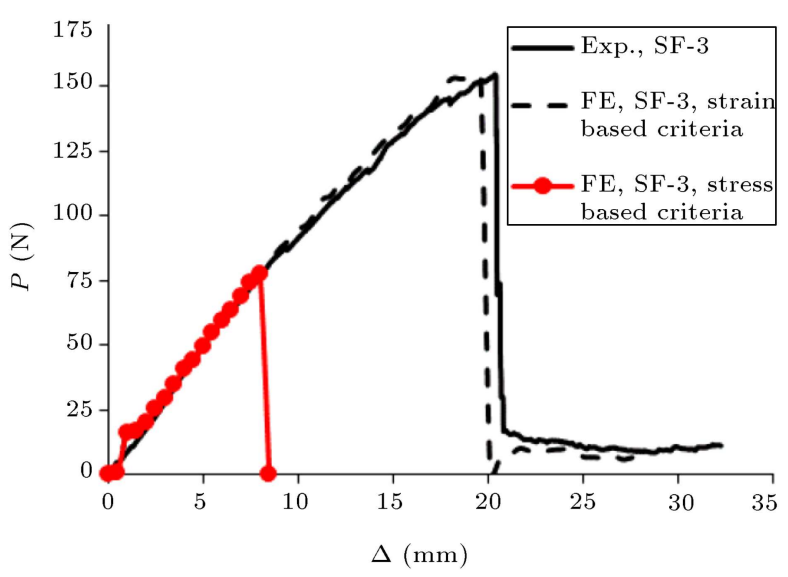

(b)

Figure 9. Load-deflection curves obtained by experiment and FE models for (a) SF-1 and (b) SF-2 specimens.

thickness. Huang [49] also reported a gradually flexural failure in the composite laminates made of carbon knitted fibres under four-point bending load. Thus, it is concluded that the failure progression processes of glass/vinylester and carbon/epoxy laminates under bending load are different.

The SF-2 specimen shows the flexural response of UD laminate in the transverse direction. The loaddeflection curve obtained by FE model and experiment for this specimen is observed in Figure 9 . Table 5 shows that by the results of the load-deflection curve, Eq. (1) estimates the initial flexural modulus as $E=4.44$
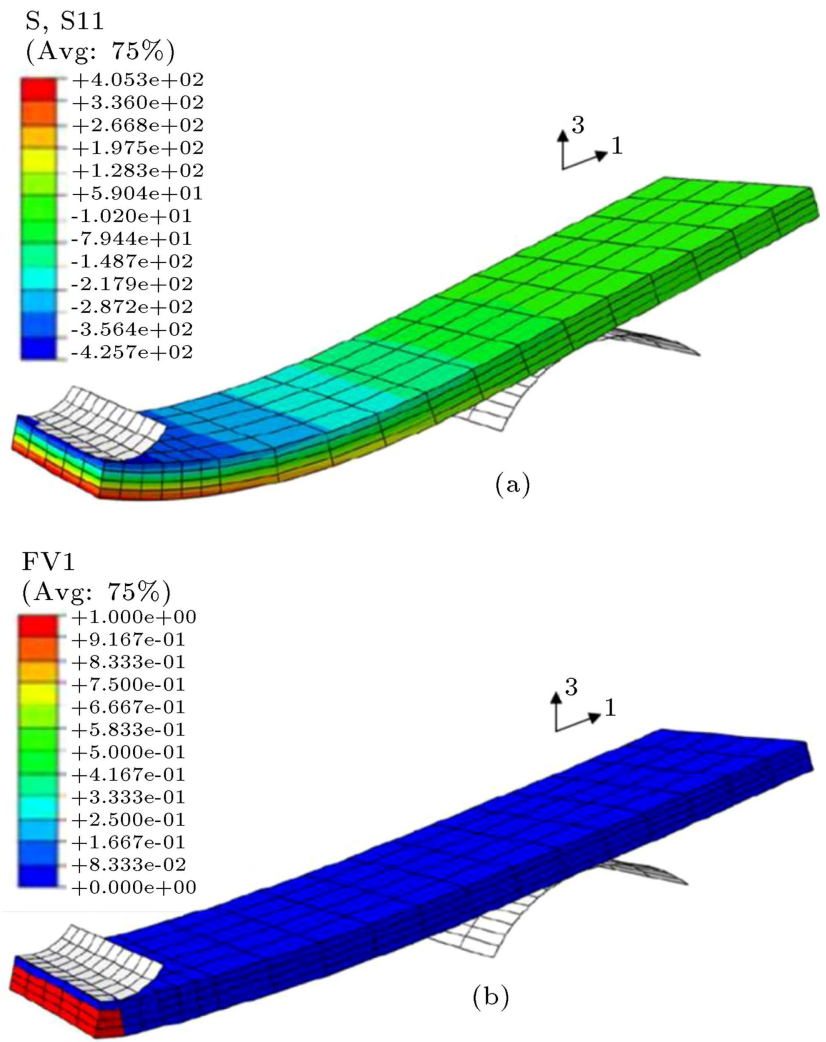

Figure 10. SF-1 specimen (a) in the ultimate state prior to cracking and (b) in the failure of the mid-span elements.

GPa. The FE model could simulate the experimental results when the modulus of elasticity was set to $E=4 \mathrm{GPa}$. These results show a large increase in the flexural modulus relative to the tensile modulus in the transverse direction of laminates (about 250\%) compared to the fibre direction. The ratio of tensile to flexural modulus can vary with various materials as well as various thicknesses of composite laminates. Roopa et al. [11] reported similar increase in the flexural modulus in the glass/vinylester laminates in comparison with the tensile modulus. The collapse of the SF-3 specimen was considered due to the midspan crack. This crack completely propagated in the thickness. The FE results showed the maximum stress on the tension side of this beam equal to $80 \mathrm{MPa}$; however, the maximum stress in the related tensile specimen was $38 \mathrm{MPa}$.

Table 5. Comparison of mechanical properties of UD specimens obtained by analytical formula and FE models.

\begin{tabular}{|c|c|c|c|c|c|c|}
\hline Properties & $\begin{array}{l}\text { Ultimate } \\
\text { tensile } \\
\text { modulus } \\
(\mathrm{MPa})\end{array}$ & $\begin{array}{l}\text { Ultimate } \\
\text { flexural } \\
\text { modulus } \\
\text { (MPa) } \\
\text { by Eq. (1) }\end{array}$ & $\begin{array}{c}\text { Ultimate } \\
\text { flexural } \\
\text { modulus } \\
(\mathrm{MPa}) \\
\text { by FE model }\end{array}$ & $\begin{array}{c}\text { Ultimate } \\
\text { tensile } \\
\text { stress } \\
(\mathrm{MPa})\end{array}$ & $\begin{array}{c}\text { Ultimate } \\
\text { flexural } \\
\text { stress } \\
\text { (MPa) } \\
\text { by Eq. (2) }\end{array}$ & $\begin{array}{c}\text { Ultimate } \\
\text { flexural } \\
\text { stress } \\
(\mathrm{MPa}) \\
\text { by FE model }\end{array}$ \\
\hline SF-1 & 12100 & 13600 & 13000 & 345 & 668 & 400 \\
\hline SF-2 & 1420 & 4440 & 4000 & 38 & 155 & 80 \\
\hline
\end{tabular}


The failure indices investigated in this research based on Hashin criteria indicate dependency of various damage modes on the shear stresses. The subject concerned here is the determination of the influence of shear stresses on the flexural failure of the composite beams. The first Hashin damage criterion is dependent on three stress components, namely, $\sigma_{11}, \sigma_{12}$, and $\sigma_{13}$. In Figure 11, the influence of each part of Hashin damage criteria in a mid-span element failing in the ultimate state is presented. Figure 11(a) shows the components of $f_{1}$ index for SF-1 specimen and Figure 11(b) shows the components of $f_{2}$ index for SF-2 specimen versus the beam mid-span deflection. These curves show ignorable influence of the shear stresses developing in the composite beams on determination of flexural failure. The outputs of the FE model simulated for SF-2 specimen indicate the value of $S_{33}$ stress equal to $4.6 \% S_{22}$ stress in the ultimate state, which means an accurate estimation of the failure in the $90^{\circ}$ layers when the out-of-plane stresses are considered in the failure criterion.

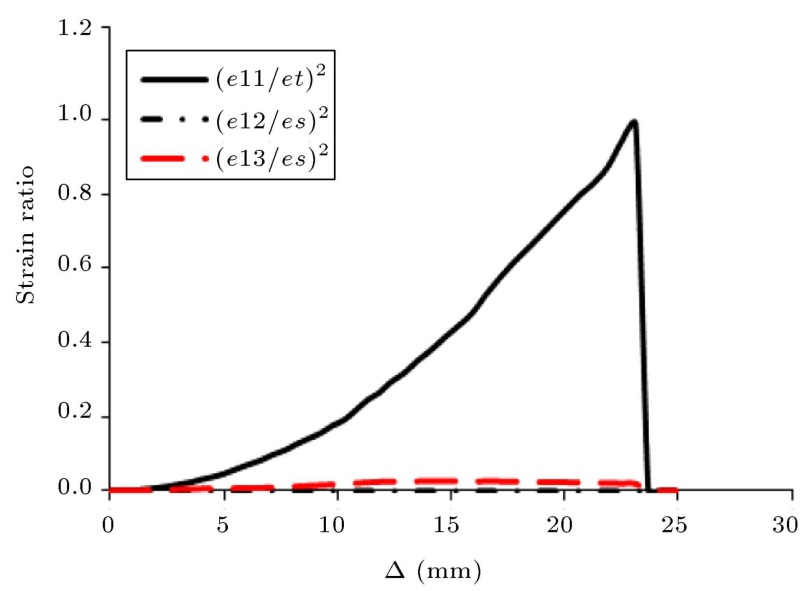

(a)

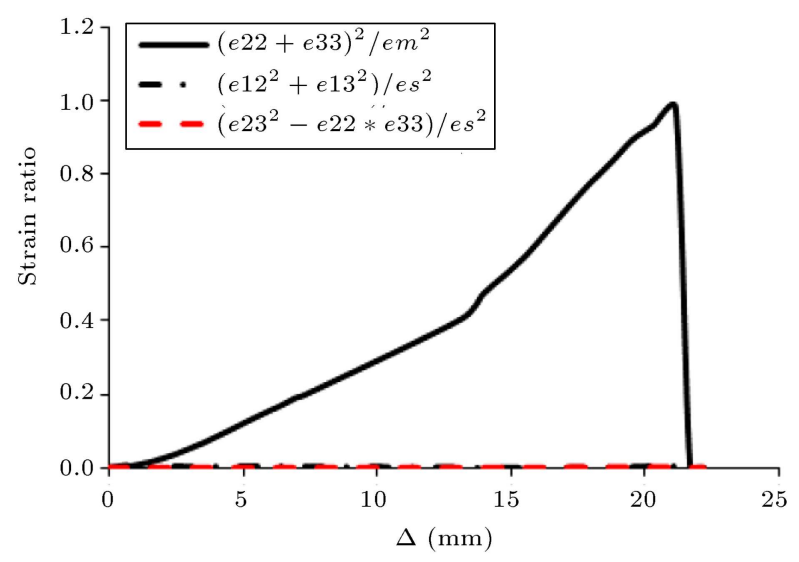

(b)

Figure 11. Components of Hashin failure criteria during the load carrying for (a) $f_{1}$ in SF-1 and (b) $f_{2}$ in SF-2 specimens.
4.2.3. Performance of asymmetric cross-ply laminates These specimens were included in the study to investigate the reliability of the analysis done for prediction of the flexural failure in non-UD laminates. Previous specimens showed that the modulus of elasticity in the fibre direction did not differ considerably in the flexural and tensile loadings. Therefore, any major change in flexural modulus of SF-2 and SF-3 specimens can be attributed to change in the modulus of $90^{\circ}$ layers. The load deflection curves of these specimens are seen in Figure 12. The results for the SF-3 specimen show that because of the perpendicular orientation of the fibres merely in one layer, the load carrying capacity of this specimen decreases considerably compared to the SF-1 specimen. The maximum stress, which is experienced in this specimen, becomes $400 \mathrm{MPa}$. Also, for the SF-4 specimen, via the change in the orientation of the first layer of laminate from $90^{\circ}$ to $0^{\circ}$, the maximum load is not increased and, instead, almost $45 \%$ reduction in the peak carrying load relative to the SF-3 specimen is observed. The FE results show that the strain-based

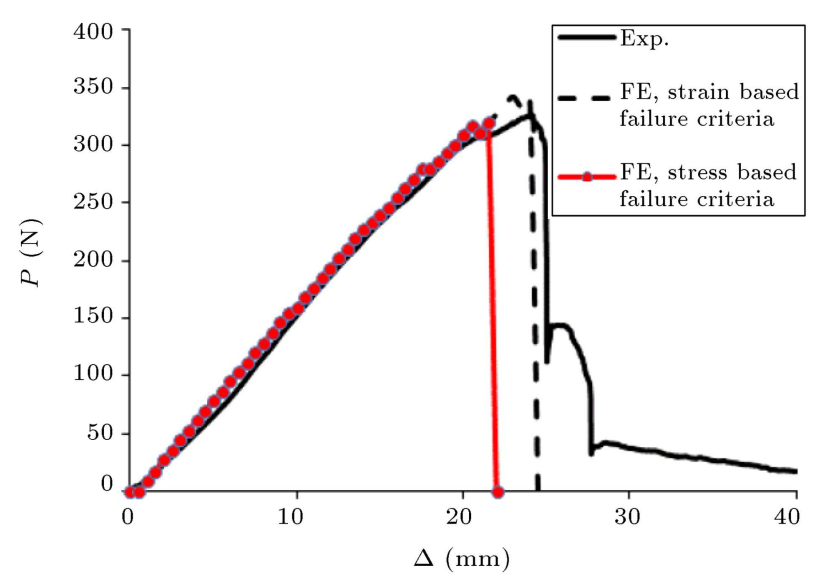

(a)

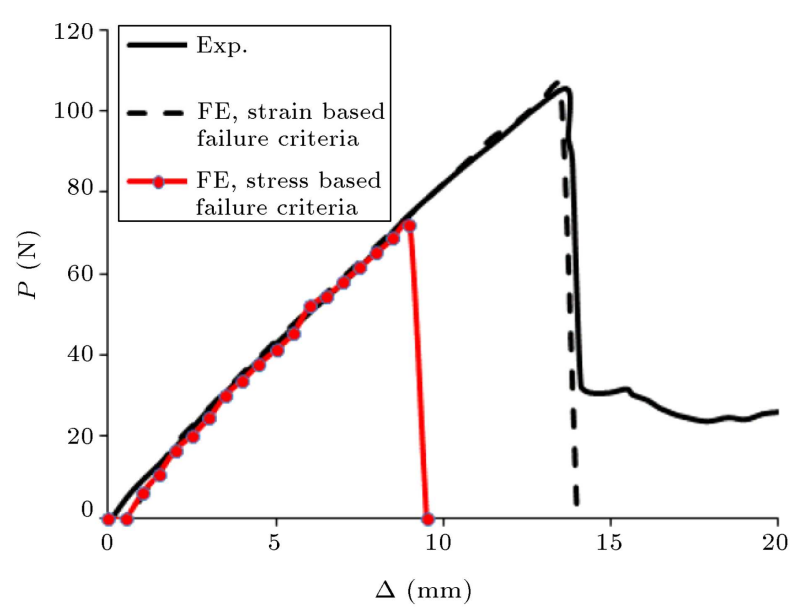

(b)

Figure 12. Load-deflection curves obtained by experiment and FE models for (a) SF-3 and (b) SF-4 specimens. 


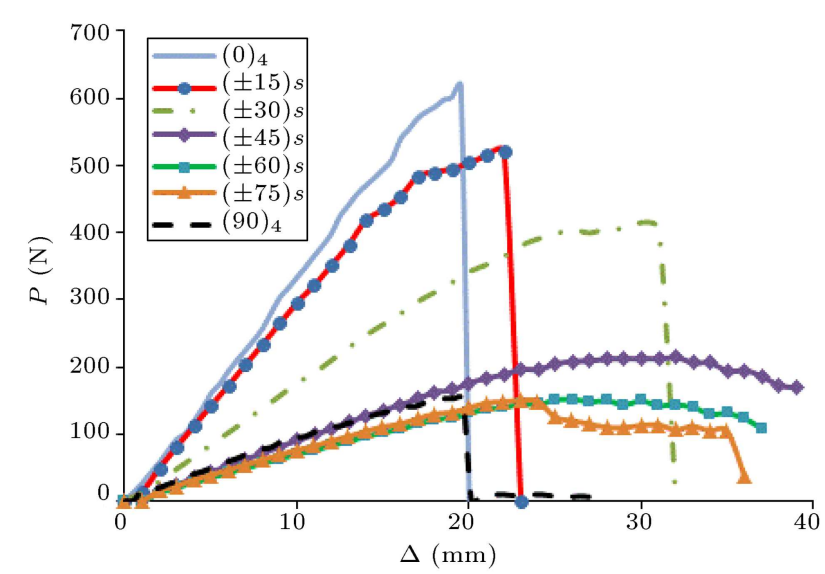

Figure 13. Load-deflection curves obtained by FE models for the angle ply laminates.

criteria based on Hashin theory can predict the collapse point of SF-3 and SF-4 specimens accurately. The results of the stress-based formula for SF-3 specimen are relatively close to the results of the strain-based formula. However, the load carrying capacity of SF4 specimen, estimated by the stress-based criteria, is considerably underestimated.

\subsection{Extended parametric studies on the angle-ply laminates}

The performance of the laminated composite beams with angle-ply layup is usually concerned in the engineering applications. In this part, the ultimate applied bending load of laminated beams, with the fibre orientation between $0^{\circ}$ and $90^{\circ}$, is investigated by FE modeling. Figure 13 presents the load-deflection of beams with $( \pm \theta)_{s}$ layups. It is seen that for the fiber orientations less than $30^{\circ}$, the load-deflection curve behaves in almost linear trend up to the ultimate load; then, the member would collapse suddenly in a brittle mode. Nevertheless, as the fibre angle increases, the variation curve tends to a nonlinear form with more ductility manner as fibre angle approaches $\theta=45^{\circ}$, $60^{\circ}$, and $75^{\circ}$.

\subsection{Energy absorption in the failure surfaces}

The unidirectional composite is treated as a bundle. Each element of the bundle consists of a number of fibres, which act together and fail together in the ultimate state [50]. In the tensile tests, the failure state usually occurs when rupture is seen in the whole section, simultaneously, but in the bending tests, the failure process of laminates has been reported dependent on the material and layup method. For example, the flexural failure seen by Huang [49] for carbon/epoxy beams is in a gradual process; however, in the research presented here, failure of the UD laminated beams is observed catastrophically. It seems that the amount of energy density, which is required for occurrence of failure in the rupture surface of the laminated beams,

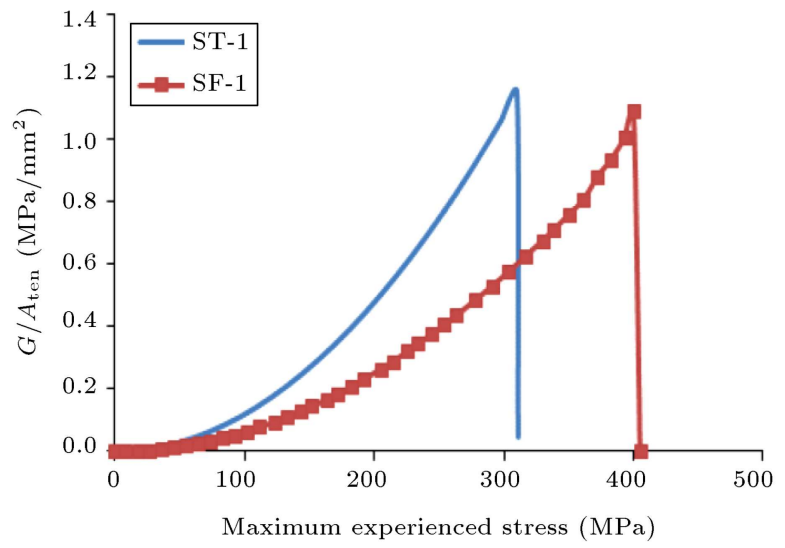

(a)

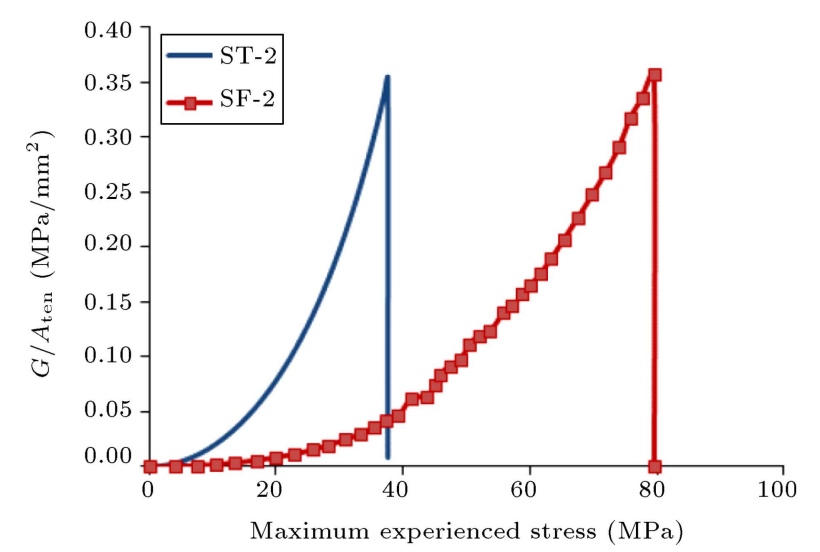

(b)

Figure 14. Progression of stored energy density in the tensile volume of the beam section versus the maximum experienced stress by the laminates with (a) (0) layup and (b) (90) 4 layup.

is equal to that measured in the tensile specimens. The energy absorbed in the tensile part of the specimens, which was compared for the tensile and bending specimens, was calculated based on the complementary free energy determined in Eq. (17). Figure 14 compares progression of the energy absorbed in the tensile part for SF-1 and ST-1 specimens in Figure 14(a) and for SF-2 and ST-2 specimens in Figure 14(b) versus the maximum experienced stress of these specimens during load carrying. $A_{t e n}$ in this figure denotes the area of the tensile part in the section of the specimens. Figure 14 indicates that although the flexural moduli and the maximum experienced stresses are different for the tensile and the bending specimens, the absorbed energies in the ruptured section are identical. This result strengthens the hypothesis of failure theories based on the absorbed energy by the material.

\section{Conclusions}

There are many reports which indicate that the flexural performance of composite laminates is different from their performance under in-plane loads. The modulus 
and/or maximum experienced stress in the majority of the composite laminates under bending and tensile load have shown different responses; however, these changes in some materials are more pronounced.

In this paper, the flexural behavior of Eglass/vinylester composite laminates has been investigated through experimental and FE studies. The objective was prediction of the load carrying capacity of composite beams in comparison with the observed axial performance with the aid of appropriate failure theories instead of Wiebull theory. The experiments consisted of tensile and bending tests. In this direction, four lay-up methods for glass/vinylester laminates were examined. Regarding the major influence of damage on the load carrying behavior of composite laminates, progressive failure analysis of the bending beams was necessary for estimation of their load carrying capacity. Thus, by means of Abaqus FE program, decohesive element was utilized for simulation of the degradation process in composite laminates. The results indicated that the strain-based failure criteria could achieve more accurate results in the estimation of the load carrying capacity than the results obtained by stress-based failure criteria. The main factor for enhancement of maximum experienced stress in the laminates under flexural load was found to be the increase in flexural modulus. Therefore, after determination of the flexural modulus by the aid of load-deflection graphs for various beams, the maximum strain measured under tensile load could predict the maximum experienced stress under bending load accurately.

\section{References}

1. Jones, R.M., Mechanics of Composite Materials, Taylor and Francis Inc., Philadelphia (1999).

2. Vinson, J.R., The Behavior of Sandwich Structures of Isotropic and Composite Materials, Technomic, Lancaster (1999).

3. Bullock, R.E. "Strength ratios of composite materials in flexure and in tension", J. Compos. Mater., 8, pp. 200-206 (1974).

4. Whitney, J.M. and Knight, M. "The relationship between tensile strength and flexure strength in fiberreinforced composites", Exp. Mech., 20(6), pp. 211-216 (1980).

5. Cattell, M.K. and Kibble, K.A. "Determination of the relationship between strength and test method for glass fibre epoxy composite coupons using Weibull analysis", Mater. Des., 22, pp. 245-250 (2001).

6. Ullah, H., Harland, A.R., and Silberschmidt, V.V. "Experimental and numerical analysis of damage in woven GFRP composites under large-deflection bending", Appl. Compos. Mater., 19, pp. 769-783 (2012).

7. Jones, R.M. "Mechanics of composite materials with different moduli in tension and compression", Final
Scientific Report, Air force office of scientific research (1978).

8. Zweben, C. "Is there a size effect in composite materials and structures?", Composites, 25, pp. 451-454 (1994).

9. Smith, D.L., Wardle, M.W., and Zweben, C. "Test methods for fiber tensile strength, composite flexural modulus and properties of fabric-reinforced laminates", In Composite Materials: Testing and Design (Fifth Conference), ASTM STP 674, S.W. Tsai (ed.), American Society for Testing and Materials, West Conshohocken, PA, pp. 228-262 (1979).

10. Tolf, G. and Clarin, P. "Comparison between flexural and tensile modulus of fibre composites", Fibre Sci. Technol., 21, pp. 319-326 (1984).

11. Roopa, T.S., Narasimha-Murthy, H., Sudarshan, K., Nandagopan, O.R., Kumar, A., Krishna, M., and Angadi, G. "Mechanical properties of vinylester/glass and polyester/glass composites fabricated by resin transfer molding and hand lay-up", J. Vinyl Addit. Techn., 2, pp. 32-45 (2014).

12. "Standard test methods for flexural properties of unreinforced and reinforced plastics and electrical insulating materials", ASTM, Designation: D790-07 (2007).

13. Greif, R. and Chapon, E. "Investigation of successive failure modes in graphite/epoxy laminated composite beams", J. Reinf. Plast. Comp., 12, pp. 602-621 (1993).

14. Kam, T.Y. and Sher, H.F. "Nonlinear and firstply failure analyses of laminated composite cross-ply plates", J. Comp. Mater., 29, pp. 463-482 (1995).

15. Echaabi, J., Trochu, F., Pham, X.T., and Ouellet, M. "Theoretical and experimental investigation of failure and damage progression of graphite-epoxy composites in flexural bending test", J. Reinf. Plas. Comp., 15, pp. 740-755 (1996).

16. Smith, P.A. and Ogin, S.L. "On transverse matrix cracking in cross-ply laminates loaded in simple bending", Compos. Part A-Appl.s, 30, pp. 1003-1008 (1999).

17. Ochoa, O. and Reddy, J.N., Finite Element Analysis of Composite Laminates, Kluwer Academic Publishers, Dordrecht (1992).

18. Garnich, M.R. and Akula, V.M.K. "Review of degradation models for progressive failure analysis of fiber reinforced polymer composites", Appl. Mech. Rev., 62, pp. 1-33 (2009).

19. Soden, P.D., Hinton, M.J., and Kaddour, A.S. "A comparison of the predictive capabilities of current failure theories for composite laminates", Comp. Sci. Technol., 58, pp. 1225-1254 (1998).

20. Hinton, M.J. and Soden, P.D. "Predicting failure in composite laminates: the background to the exercise", Comp. Sci. Technol., 58, pp. 1001-1010 (1998). 
21. Soden, P.D., Hinton, M.J., and Kaddour, A.S. "Lamina properties, lay-up configurations and loading conditions for a range of fiber-reinforced composite laminates", Comp. Sci. Technol., 58, pp. 1011-1022 (1998).

22. Farrokhabadi, A., Hosseini-Toudeshky H., and Mohammadi, B. "A generalized micromechanical approach for the analysis of transverse crack and induced delamination in composite laminates", Compos. Struct., 93, pp. 443-455 (2011).

23. Sadeghi, G., Hosseini-Toudeshky, H., and Mohammadi, B. "An investigation of matrix cracking damage evolution in composite laminates-Development of an advanced numerical tool", Compos. Struct., 108, pp. 937-950 (2014).

24. Abisset, E., Daghia, F., and Ladevéze, P. "On the validation of a damage mesomodel for laminated composites by means of open-hole tensile tests on quasiisotropic laminates", Compos. Part A-Appl.s, 42, pp. 1515-1524 (2011).

25. Ladèveze, P. and Lubineau, G. "An enhanced mesomodel for laminates based on micromechanics", Compos. Sci. Technol., 62, pp. 533-541 (2002).

26. Yokozeki, T., Aoki, Y., and Ogasawara, T. "Experimental characterization of strength and damage resistance properties of thin-ply carbon fiber/toughened epoxy laminates", Compos. Struct., 82, pp. 382-389 (2008).

27. Yokozeki, T., Kuroda, A., Yoshimura, A., Ogasawara, T., and Aoki, T. "Damage characterization in thinply composite laminates under out-of-plane transverse loadings", Compos. Struct., 93, pp. 49-57 (2010).

28. Sathish, S., Prasath, J., Reddy, K.S., and Naik, N.K. "Damage evolution in delaminated woven fabric Eglass/epoxy composite plates under transverse static patch loading", Int. J. Damage Mech., 22(7), pp. 9821005 (2012).

29. Ellul, B., Camilleri, D., and Betts, J.C. "A progressive failure analysis applied to fiber reinforced composite plates subject to out-of-plane bending", Mech. Compos. Mater., 49(6), pp. 605-620 (2014).

30. Iannucci, L. and Ankersen, J. "An energy based damage model for thin laminated composites", Compos. Sci. Technol., 66, pp. 934-951 (2006).

31. Iannucci, L. and Willows, M.L. "An energy based damage mechanics approach to modeling impact onto woven composite materials: Part II. Experimental and numerical results", Compos. Part A-Appl.s, 38, pp. 540-554 (2007).

32. Doudican, B.M., Doudican, B.M., Zand, B., Amaya, P., Butalia, T.S., Wolfe, W.E., and Schoeppner A.G. "Strain energy based failure criterion: comparison of numerical predictions and experimental observations for symmetric composite laminates subjected to triaxial loading", J. Compos. Mater., 47(6-7), pp. 847-866 (2012).

33. McCartney, L.N. "Energy-based prediction of progressive ply cracking and strength of general symmetric laminates using an homogenisation method", Compos. Part A-Appl.s, 36, pp. 119-128 (2005).

34. McCartney, L.N. "Energy-based prediction of failure in general symmetric laminates", Eng. Fract. Mech., 72, pp. 909-930 (2005).

35. Mines, R.A.W. and Alias, A. "Numerical simulation of the progressive collapse of polymer composite sandwich beams under static loading", Compos. Part AAppl.s, 33, pp. 11-26 (2002).

36. Irhirane, E.H., Echaabi, J., Aboussaleh, M., and Hattabi, M. "Matrix and fibre stiffness degradation of a quasi-isotrope graphite epoxy laminate under flexural bending test", J. Reinf. Plast. Comp., 28(2), pp. 201-223 (2009).

37. Standard Test Method for Tensile Properties of Polymer Matrix Composite Materials, ASTM, Designation: D3039/D3039M-00 (2000).

38. Batra, R.C., Gopinath, G., and Zheng J.Q. "Damage and failure in low energy impact of fiber-reinforced polymeric composite laminates", Compos Struct., 94, pp. 540-547 (2012).

39. ABAQUS/Analysis User's Manual, Version 6.10, ABAQUS Inc. (2010).

40. Camanho, P.P. and Davila, C.G., Mixed-Mode Decohesion Finite Elements for the Simulation of Delamination in Composite Materials, NASA/TM-2002-211737 (2002).

41. Hashin, Z. "On elastic behavior of fibers reinforced materials of arbitrary transverse phase geometry", $J$. Mech. Phys. Solids, 13, pp. 119-134 (1965).

42. Hashin, Z. and Rotem, A. "A fatigue criterion for fiberreinforced materials", J. Compos. Mater., 7, pp. 448464 (1973).

43. Lapczyk, I. and Hurtado, J.A. "Progressive damage modeling in fiber-reinforced materials", Compos. Part A-Appl.s, 38, pp. 2333-2341 (2007).

44. Barbero, E.J., Cosso, F.A., Roman, R., and Weadon, T.L. "Determination of material parameters for abaqus progressive damage analysis of E-glass epoxy laminates", Compos. B-Eng., 46, pp. 211-220 (2013).

45. Maimi, P., Camanho, P.P., Mayugo, J.A., and Dávila, C.G. "A continuum damage model for composite laminates: Part I - constitutive model", Mech. Mater., 39, pp. 897-908 (2007).

46. Bazănt, Z.P. and Oh, B.H. "Crack band theory for fracture of concrete", Mater. Struct., 16, pp. 155-177 (1983).

47. Maimi, P., Camanho, P.P., Mayugo J.A., and Dávila, C.G. "A thermodynamically consistent damage model for advanced composites", NASA/TM-2006-214282 (2006).

48. Wisnom, M.R. and Atkinson, J.W. "Reduction in tensile and flexural strength of unidirectional glass fibre-epoxy with increasing specimen size", Compos. Struct., 38(1-4), pp. 405-411 (1997). 
49. Huang, Z.M. "Progressive flexural failure analysis of laminated composites with knitted fabric reinforcement", Mech. Mater., 36, pp. 239-260 (2004).

50. Wisnom, M.R. "The relationship between tensile and flexural strength of unidirectional composites", $J$. Compos. Mater., 26, pp. 1173-1180 (1992).

\section{Appendix A}

The non-zero components of $\mathbf{C}_{\mathbf{d}}$ matrix are derived as:

$$
\begin{aligned}
& M_{11}=\frac{E_{1}}{D} \cdot\left(1-d_{f}\right) \cdot\left[1-\nu_{23} \nu_{32} \cdot\left(1-d_{m}\right)^{2}\right] \\
& M_{12}=\frac{E_{1}}{D} \cdot\left(1-d_{f}\right) \cdot\left(1-d_{m}\right) \cdot\left[\nu_{21}+\nu_{23} \nu_{31}\left(1-d_{m}\right)\right]
\end{aligned}
$$

$$
M_{13}=\frac{E_{1}}{D} \cdot\left(1-d_{f}\right) \cdot\left(1-d_{m}\right) \cdot\left[\nu_{31}+\nu_{21} \nu_{32}\left(1-d_{m}\right)\right]
$$

$$
M_{21}=\frac{E_{2}}{D} \cdot\left(1-d_{f}\right) \cdot\left(1-d_{m}\right) \cdot\left[\nu_{12}+\nu_{13} \nu_{32}\left(1-d_{m}\right)\right],
$$

$$
M_{22}=\frac{E_{2}}{D} \cdot\left(1-d_{m}\right) \cdot\left[\nu_{13} \nu_{31}\left(d_{f}+d_{m}-d_{f} d_{m}-1\right)+1\right],
$$$$
M_{23}=\frac{E_{2}}{D} \cdot\left(1-d_{m}\right)^{2} \cdot\left[\nu_{32}+\nu_{12} \nu_{31}\left(1-d_{f}\right)\right]
$$

$M_{31}=\frac{E_{3}}{D} \cdot\left(1-d_{f}\right) \cdot\left(1-d_{m}\right) \cdot\left[\nu_{13}+\nu_{12} \nu_{23}\left(1-d_{m}\right)\right]$,

$$
M_{32}=\frac{E_{3}}{D} \cdot\left(1-d_{m}\right)^{2} \cdot\left[\nu_{23}+\nu_{13} \nu_{21}\left(1-d_{f}\right)\right]
$$

$$
M_{33}=\frac{E_{3}}{D} \cdot\left(1-d_{m}\right) \cdot\left[\nu_{12} \nu_{21}\left(d_{f}+d_{m}-d_{f} d_{m}-1\right)+1\right],
$$

$$
M_{44}=\frac{\left(1-d_{\mathrm{SL}}\right)}{G_{12}}, \quad M_{55}=\frac{\left(1-d_{\mathrm{SL}}\right)}{G_{13}},
$$

$$
\begin{aligned}
M_{66}= & \frac{\left(1-d_{\mathrm{ST}}\right)}{G_{23}} \\
D=1 & -\left(1-d_{f}\right)\left(1-d_{m}\right)\left(\nu_{12} \nu_{21}+\nu_{13} \nu_{31}\right) \\
& -\nu_{23} \nu_{32}\left(1-d_{m}\right)^{2} \\
& -\left(1-d_{f}\right)\left(1-d_{m}\right)^{2}\left(\nu_{12} \nu_{23} \nu_{31}+\nu_{13} \nu_{32} \nu_{21}\right)
\end{aligned}
$$

\section{Biographies}

Ali Reza Nazari is PhD candidate in the Department of Civil and Environmental Engineering at Amirkabir University of Technology. He received his BS degree from Isfahan University of Technology and MS from Amirkabir University of Technology. His research interest includes composite structures, structural analysis using FEM, experimental methods in structural engineering, damage detection especially in the composite structures, and rehabilitation of structural members using FRP materials.

Mohammad Zaman Kabir is Professor in the Department of Civil and Environmental Engineering at Amirkabir University of Technology, Tehran, Iran . He received his BS and MS degrees from Amirkabir University of Technology and $\mathrm{PhD}$ from Waterloo University in Canada. His research interest includes structural stability, structural analysis using FEM, experimental methods in structural engineering, composite structures, structural optimization, damage detection, and rehabilitation of structures.

Hossein Hosseini-Toudeshky is Professor of Structural Integrity and Component Life Assessment in the Department of Aerospace Engineering at Amirkabir University of Technology, Tehran, Iran. He received his BS and MS degrees from Isfahan University of Technology and PhD from the University of New South Wales in Australia. His research interest includes structural integrity, creep and fatigue life assessment of components, progressive damage analyses, continuum damage methods, multi-scale modeling, material characterization, and composite structures. 